\title{
Tríada de Rigler
}

\section{Rigler's triad}

\section{Javier Chinelli ${ }^{1}$, Gustavo Rodríguez ${ }^{2}$}

DOI $10.31837 /$ cir.urug/4.2.9

Recibido: 05 de mayo de 2020

Aceptado: 12 de junio de 2020

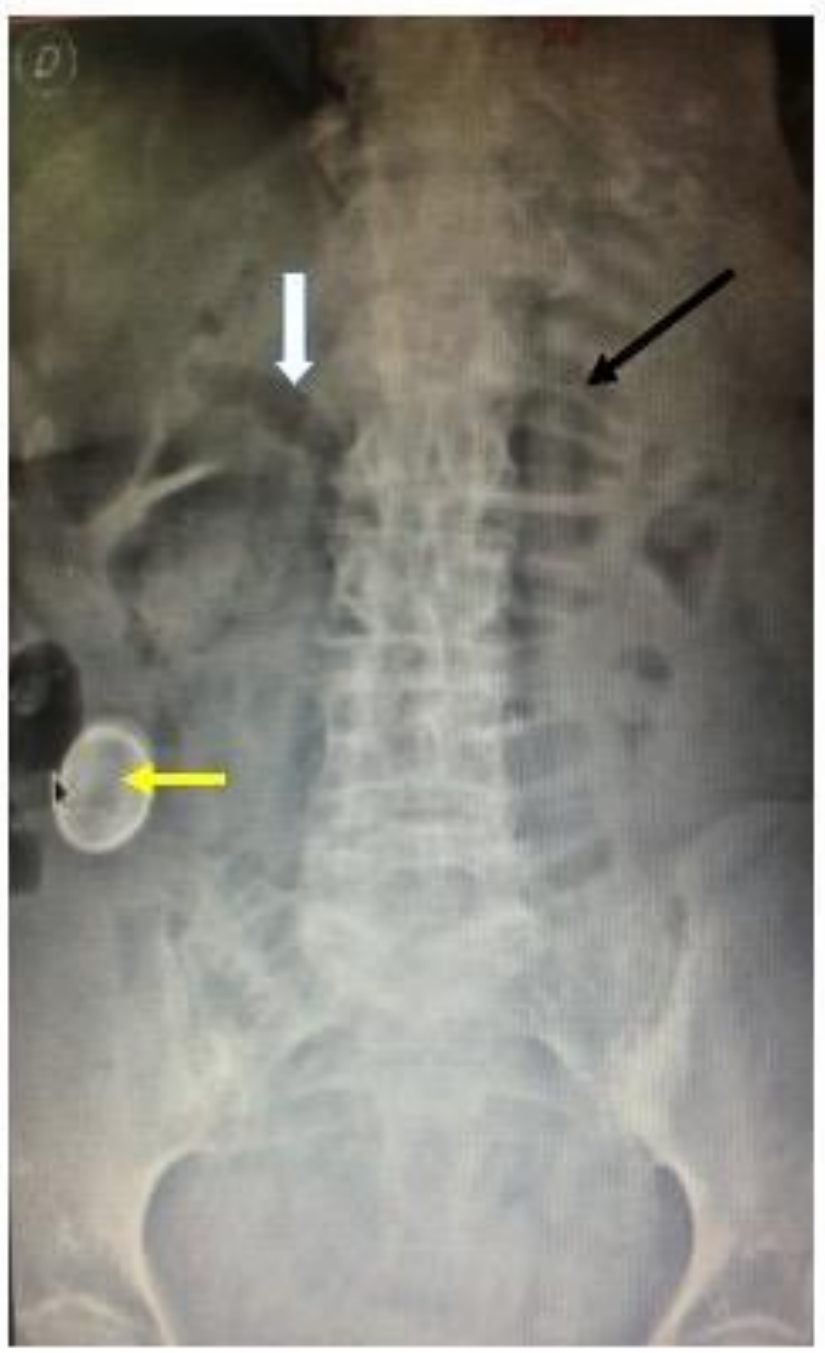

1-2 Clínica Quirúrgica 2, Hospital Maciel, Facultad de Medicina, Universidad de la República, Montevideo, Uruguay jchinelli01@gmail.com 
Paciente de 68 años, sin antecedentes quirúrgicos.

Ingresó a Emergencia con cuadro clínico de oclusión intestinal. Se solicitó radiografía simple de abdomen (solamente se obtuvo en decúbito), observándose la presencia de la tríada radiológica de Rigler, patognomónica del ileo biliar.

Se señalan los 3 elementos: asas de delgado dilatadas (flecha negra), aerobilia (flecha blanca) y el cálculo calcificado ectópico en la fosa ilíaca derecha (flecha amarilla).

El íleo biliar es la oclusión intestinal como consecuencia de la migración de un cálculo biliar a través de una fístula bilio-digestiva y su impactación, frecuentemente a nivel de la válvula ileo-cecal. Habitualmente se trata de una fístula colecisto-duodenal, aunque también puede tratarse de una fístula colecisto-colónica.

El cuadro clínico clásicamente descrito es el de una oclusión intermitente, siendo más frecuente en pacientes añosos, con larga historia de litiasis biliar sintomática. 